\title{
Confidence in Online Degree Programs
}

\author{
Tayeb Basta, Senior Member, IACSIT
}

\begin{abstract}
Electronic learning is a type of education where the medium of instruction is information and communication technologies (ICT). E-learning can be defined as the application of information and communication technologies to core institutional functions such as administration, materials development and distribution, course delivery and tuition, and the provision of learner services such as advising, prior learning assessment and program planning.

E-Learning can be either blended learning in which the technology is used to enhance the face-to-face teaching, or it can be purely online learning, that is, the delivery of courses completely through information and communication technologies.

This paper reports the different point of view about e-learning education in general and its credibility in particular. It demonstrates that one of the important factors of the e-learning credibility is the quality of assessment employed to measure how learners perceive the information. The paper recommends a way by which such assessments should be held to preserve the educational standards on one hand, and guarantee confidence in online learning, on the other.
\end{abstract}

Index Terms - Online, e-learning, e-assessment, confidence.

\section{INTRODUCTION}

Electronic learning (or eLearning or e-learning) is a type of education where the medium of instruction is information and communication technologies (ICT). E-learning, as defined in [1], is the application of information and communication technologies to core institutional functions such as administration, materials development and distribution, course delivery and tuition, and the provision of learner services such as advising, prior learning assessment and program planning. E-learning is used interchangeably in a wide variety of contexts. 1) In companies, it refers to the strategies that use the company network to deliver training courses to employees. 2) In the USA, it is defined as a planned teaching/learning experience that uses a wide spectrum of technologies, mainly Internet or computer-based, to reach learners. 3) In most Universities, e-learning is used to define a specific mode to attend a course or programs of study where the students rarely, if ever, attend face-to-face for on-campus access to educational facilities because they study online. The general consensus is that technology will play a large role in the planning, development and delivery of the curriculum of the contemporary university and the challenge for institutions is to make decisions now that will set them on the preferred and appropriate path to the future. The growth of e-learning is directly related to:

Manuscript received October 22, 2012; revised April 5, 2013.

Tayeb Basta is with College of Computing, Al Ghurair University, PO Box 37374 Dubai, United Arab Emirates (e-mail: tayebasta@gmail.com).
1) The increasing access to information and communications technology, as well as its decreasing cost.

2) The capacity of information and communications technology to support multimedia resource-based learning and teaching.

3) The growing numbers of teachers who are increasingly using information and communications technology to support their teaching.

4) The contemporary student populations who have grown up using information and communications technology and who also expect to see it being used in their educational experiences.

E-Learning is seen as a future application worldwide, promoting lifelong learning by enabling learners to learn anytime, anywhere and at the learner's own pace. Students are able to communicate with classmates and lecturers, visit web sites and view course material regardless of their time and location. E-learning has enabled universities to expand on their current geographical reach, to capitalize on new prospective students and to establish themselves as global educational providers.

E-Learning can be either blended learning that is the use of technology to enhance the face-to-face teaching, which means the integrated combination of traditional (face-to-face) learning with web-based online approaches. Or it can be purely online learning that is the delivery of courses completely through communication and information technologies. In the latter case students are able to acquire the necessary knowledge remotely and without meeting with their lecturers. Convenient and simple to use, online learning allows students to take a semester-long class from anywhere in the world as long as they have access to the Internet.

New class lecture videos are made available to watch when students have time. They interact with classmates and instructors through e-mail and the Web, and review and complete the scheduled assignments wherever they are most comfortable.

The rest of the paper is organized as follows: Section II discusses the paradoxes of e-learning in higher education institutions. Section III reports on the success of blended e-learning. Sections IV is about the role of assessment in supporting education, Section V emphasizes online assessment limitations. Section VI is about the credibility of online degrees. Finally the paper concludes by advocating the introduction of summative assessment in online learning.

\section{PARADOXES OF E-LEARNING INFRASTRUCTURE IN HIGHER} EDUCATION INSTITUTIONS

Nowadays the introduction of e-learning in higher 
education institutions becomes a necessity and no longer an option. Universities are required to reshape their courses, professional practice and administrative procedures to address the emerging demands of this new approach. In [2], Volery argues that the fast expansion of the Internet and related technological advancements, in conjunction with limited budgets and social demands for improved access to higher education, has produced a substantial incentive for universities to introduce e-learning courses. He added that if universities do not embrace e-learning technology that is readily available, they will be left behind in the pursuit for globalization. Ribiero [3] argues that if universities are to maximize the potential of e-learning as a means of delivering higher education, they must be fully aware of the critical success factors concerned with introducing online models of education. In [4], Darling advocates that e-learning is a valuable strategic business tool, that when implemented properly could modernize higher education, but when deciding an effective strategy it is imperative to consider that distance learning is a means to an end, not the end itself. Among the objectives of introducing e-learning is to open opportunities before learners to acquire knowledge with less cost. This easing should be a consequence of ease of adoption and implementation and use of the new technology. Unfortunately, experts of the discipline are reporting different experiences in real world situations. Hartley [5] details that any university incorporating e-learning initiatives into organizational strategy must take into consideration the following: the financial constraints of the strategy, suitability of the technology, implementation of the technology and the range of e-learning requirements within the institution. If sufficient attention is given to all these considerations, the university is in control of its online learning future.

Guri-Rosenblit [6] reports that the paradoxes in managing e-learning relate to the differential infrastructure and readiness of different types of higher education institutions to utilize the technologies' potential; the extent to which the 'old' distance education technologies and the new technologies replace teaching/learning practices in classrooms; the role of real problems, barriers and obstacles in applying new technologies; the impact of the new technologies on different student clienteles; information acquisition versus knowledge construction in higher education; cost considerations; the human capacity to adapt to new learning styles in the face of rapid development of the technologies; and the organizational cultures of the academic and corporate worlds. Many commentators describe the relative benefits of e-learning in higher education; however, there are ramifications for unprepared, technology focused institutions, when trying to implement distance learning courses. O'Hearn [7] contends that university structures are rigid and unproven, regarding the incorporation of technological advancements. Shirley [8] reported that the increased investment in e-learning initiatives in Australian universities appears to have occurred as a reaction to the view that higher education is in crisis. The crises center around three issues; access to education, the cost of providing education, and dwindling public revenues. It is often argued that ICT is a sophisticated tool to design, develop, implement, and deliver education programs. Bennett and McIntyre [9] argued that this is not the case in many online programs. "It is often apparent that technical issues actually dictate the content and its delivery. Online education has been strongly influenced by the availability of the latest technology, and in many instances colleges and universities now find themselves locked into expensive licensing contracts for software that on reflection does not seem 'comfortable' for subject delivery or use by students, academics or administrators."

\section{SUCCESS OF BLENDED E-LEARNING}

Very few e-learning observers drew a pessimistic perspective about e-learning and about incorporating information and communication technologies into the education process in general. However, most researchers and practitioners around the world agreed upon the success of e-learning in many contexts including in higher education. In blended learning the long history and traditions of face-to-face learning and advancement of information and communication technologies in e-learning come together to enhance the way knowledge is processed and captured. However, a number of concerned people have reported some reservations about online learning credibility and its placement as an alternative to face-to-face learning. Institutional rationales for blended e-learning were highly contextualized and specific to each institution. They included: flexibility of provision, supporting diversity, enhancing the campus experience, operating in a global context and efficiency. For instance the following study reports about some success of blended e-learning in the United States. The Pew Foundation has sponsored a study to investigate how large enrollment and introductory courses can be effectively redesigned using a blended format. The program involved 30 institutions and 20 of which reported improved learning outcomes while 10 reported no significant difference [10]. In addition, 18 of the study institutions demonstrated a decrease in student drop-failure-withdrawal rates compared to the face-to-face. Only sections out of the 24 institutions which measured reported changes in drop-failure-withdrawal rate.

The University of Central Florida has been involved in an ongoing evaluation of the Web and web-enhanced courses since the inception of their Distributed Learning initiative in the fall of 1996 [11]. These evaluation studies indicate that on average, blended learning courses have higher success rates and lower withdrawal rates than their comparable face-to-face courses. The studies also show that student retention in blended courses is better than in totally online courses and equivalent to that of face-to-face courses. Qualitative research studies at the University of Wisconsin in Garnham and Kaleta [12] suggested that students learn more in blended courses than they do in comparable traditional class sections. Teachers responsible for the blended sections report that students wrote better papers, performed better on exams, produced higher quality projects, and were capable of more meaningful discussions on course material. Spika [13] added that the increased opportunities for self-directed learning in the blended model helped students develop project and time management skills. In 2002, Harvard Business School faculty DeLacey and Leonard reported that students not only learned more when online sessions were added to traditional courses, 
but student interaction and satisfaction improved as well. Thomson and NETg released a 2003 white paper that reported speedier performance on real world tasks by people who learned through a blended strategy faster than those studying through e-learning alone [14].

\section{ASSESSMENT IS A KEY SUCCESS FACTOR FOR CURricula}

As it becomes a general consensus that the new technology is improving the delivery of course process. It facilitates life for learners in terms of time, cost and efforts. This agreement has to take into consideration that courses are different in their contents and in the way they are perceived by learner. The technology used to deliver mathematics is different from the one to deliver medicine. Both of these are different from the technology to deliver grammar. If this remark is not taken into consideration, we will reach a stage were qualified people are enable to think freely to solve a given problem unless the problem is formulated in true-false or multi-choice questions model. In addition to the above remark, using ICT to teach some disciplines such arts, painting, calligraphy and the like is impractical. Also, courses involving practical work cannot be delivered entirely online. The other important factor that has been slightly treated in the e-learning literature is the assessment component. Moreover, whenever assessment is referred to, students' grading is explicitly discarded from the discussion. Evidently, assessment is a key success factor for any curriculum. No one may reasonably argue that learning in general and e-learning in particular can achieve its goals without assessment; and more precisely, without student learning assessment. The objectives of student assessment can be classified into two main categories: 1) assessment to evaluate the learning process in order to discover weaknesses that require some remedy, or to enhance the quality of such a process, 2) assessment of the outcomes of academic programs which offer degrees.

In the former case, authentication is not a strong requirement as long as learners are not expected to cheat themselves in the first place. Their participation is to improve the learning process without any influence whatsoever on their learning progress. In the latter case, learners' perception is the subject matter of the assessment and by consequence it requires more attentions. Assessment is the process used to collect information about student progress toward educational goals. The particular form of an assessment depends on what is being assessed and on what the outcomes of the assessment will be applied to. Assessments can range from small-scale assessments that teachers use in the classroom to obtain day-to-day information about student progress; through medium-scale assessments that used to evaluate the effectiveness of schools or educational programs; all the way to large-scale assessments that state or national bodies use to assess the degree to which students have met large educational goals. Assessment can have many different forms. Besides the traditional examination process in which students are tested by teachers there are:

1) Group assessment where teams assess the work of their fellows.
2) Peer assessment involves students assessing the performance of other students.

3) Self assessment where a student assesses his/her own progress.

Assessment can be either summative or formative. The summative assessment is a means to gauge, at a particular point in time, student learning relative to content standards. Although the information that is gleaned from this type of assessment is important, it can only help in evaluating certain aspects of the learning process because they are spread out and occur after instruction every few weeks, months, or once a year. Summative assessments are tools to help evaluate the effectiveness of programs, institution improvement goals, alignment of curriculum, or student placement in specific programs. Formative Assessment is part of the instructional process. When incorporated into classroom practice, it provides the information needed to adjust teaching and learning while they are happening. In this sense, formative assessment informs both teachers and students about student understanding at a point when timely adjustments can be made. These adjustments help to ensure that students achieve targeted standards-based learning goals within a set time frame. Both summative and formative assessments complement each other for achieving the evaluation of students' learning as well as improving programs quality. For the purpose of evaluating academic programs, the programs are considered to be a set of courses. Each course is subdivided into parts which include a number of chapters. Weights are assigned to the different parts of the course. Summative and formative assessments are spread along the parts of the course. Students' grades are summarized and checked against the different weighted parts of the course. Students' marks obtained in the different courses parts are aligned with course objectives. Then students' achievements in the different courses are aligned with the program objectives. Such activities are used as a gauge to restructuring courses and place more attention on some of its parts than others, and consequently ameliorate the program quality.

In their project to examine the characteristics of assessment environments in three contrasting universities in each of three contrasting disciplines, and relating these characteristics to several features of students' learning responses Gibbs and Dunbat-Goddet [15] observed that students' experience was negative in most respects when there was a high volume of summative assessment of a wide variety of kinds, and little formative-only assessment or oral feedback. Even though they ascertain that where both summative and formative assessment was low, student effort and coverage of the syllabus was low. While summative assessment is distinguished to allow students to be highly selective in the components of the syllabus they actually study, and highly selective about what they put their time into, it is an important educational component which is missing from online learning. Introducing summative assessment in online learning sustains the credibility of online learning in the eyes of employers.

\section{ONLINE ASSESSMENT LIMITATIONS}

Conole and Warburton [16] assert that when online 
assessment (e-assessment) tasks are designed with due care and attention, research suggests that it is possible to assess the deepest levels of student learning. Such a statement requires the distinction between two types of assessments; formative and summative. Whenever formative assessment is considered, there is no difference between traditional and online assessments. When talking about summative assessment in real-world situations the following points was raised by the Commission for Academic Accreditation in the UAE [17].

Most online tests are limited to true-false or multi-choice questions. This question pattern cannot be adopted for all subjects in the curriculum. It can be used to gauge students' ability to answer questions relevant to grammar rules, mathematical expressions evaluation, functionalities of a given device, and the like. However, it falls short to cope with reasoning questions like proving a mathematical theorem, finding a logical error in a computer program, or evaluating the quality of a literature essay.

The other important side of the question is the credibility of such assessments. If security of online transactions is one of the challenging subjects in our day-to-day activities, how are exams can be held online?

It may be arguable that the examinee is sitting in front of a camera and answering questions online. This is true; but the questions can be answered and posted through a keyboard and a mouse operated by someone else.

It can be said that the examinee is answering by mobile phone and authenticated by his/her voice. This is also true, but the answers can be exposed to him/her by a third party.

It can be argued that online tests can incorporate any type of questions. This is true; however questions that involve reasoning require more time for thinking. Such amount of time can be used to seek answers from a third party which might be the Internet itself.

Among the disadvantages of web-based assessment identified by Booth et al. [18] is the lack of security in assessment situations.

The authors [18] suggested solutions for the security problem to "include accredited assessment centers, the use of passwords, and invigilation at summative tests, frequent testing of students and also a close monitoring of student records to detect wild fluctuations. A new development is the availability of biometric authentication software that is capable of identifying students from the rhythm of their keystrokes. Also, in future, web cameras and voice recognition software could be incorporated into systems to supervise students during tests."

However, currently the authentication of students taking tests at remote locations is still a problem [19].

In their guidebook for e-Learning Accreditation Standards [17], the Academic Accreditation Commission in the UAE indicates that the following quality criteria should be met when online assessment is to take place:

1) Integrity: This can be achieved by ensuring that students do not use unfair means during an assessment. In the on-line environment, we can ensure this by blocking access to web sites that might provide information for students to answers the questions.
2) Security: This can be achieved by ensuring that unauthorized individuals are not permitted access to assessment questions and results. We can ensure this by having passwords that determine access to the tests in the on-line medium.

3) Availability: This can be achieved by ensuring that while the assessment is being administered, access to the assessment and the required resources is continuously maintained.

The Committee for Academic Accreditation in the UAE [17] developed appropriate guidelines to implement measures aimed at ensuring the above criteria for traditional assessment:

1) Preventing individuals who do not carry valid identity cards from entering the assessment centre

2) Ensuring that students do not discuss questions

3) Preventing access to machines such as copiers and scanners

4) Preventing access to the Internet and other technology resources and tools

5) Developing multiple assessment questions mapping to each learning objective, and preparing alternative examinations.

It is widely recognized that information security is an important issue to the Internet users. The following are tips example for preventing security breaches from TOEFL examinations [20]:

1) Test materials:

- Never leave test manuals unattended.

- Distribute and collect test books individually.

- Ensure that no examinee leaves the room with test materials.

- Ensure that no examinee copies, removes, records or photographs any portion of the test materials.

2) Impersonation:

- Check examinees' identification and documents thoroughly at the time they enter the assigned testing rooms and as they return the completed test materials.

- Limit the number of examinees permitted to leave the testing room at any one time.

3) Copying:

- Never allow examinees to select their own seats.

- Randomly assign examinees to specific seats in each testing room.

- Seat examinees a minimum of 1.5 meters apart.

- Seat all examinees facing the same direction in each room.

- Document in writing the examinee seating plan, showing candidate's name, location, and serial number of test book.

- Observe and check examinees' answer sheets throughout the testing session to ensure that they are properly gridding with a Number 2 (soft lead) pencil.

4) Collecting Answer Sheets:

- Check the first four letters of the gridded name against the first four letters of the printed name when collecting each answer sheet.

- Check examinees' identification and documents thoroughly at the time they return the completed testing 
materials.

5) Prohibited Materials:

- Dictionaries Rulers Calculators

- Mobile telephones Personal computing devices Pagers

- Audio recording devices Photo or video recording devices

Evidently, none of the above criteria can be enforced for summative online assessment. The use of e-assessment raises issues on verification of student identity, and appropriate measures need to be in place to ensure an absence of impersonation or plagiarism. Cross-referencing and correlation analysis between performance on written examinations and continuous assessment may be undertaken. Examination processes should verify attainment of learning objectives by a person who is identifiable as the person registered for the course. Institutions offering programs internationally should ensure that their mechanisms for verification of identity can be operated in all territories in which they register students. Carefully investigating the assessment in both face-to-face and online leaning, it is evident that formative assessment can have the same content as well as the same achievements in both types of learning; furthermore the use of technology in online learning may provide for well organized assessment. The only distinction in this context is whereas summative assessment is an essential component in traditional learning it is not taken seriously in online learning. This difference entails the credibility diminution of online degrees. For the purpose of boosting their online degrees credibility, higher education institutions are required to plan for periodically held examinations at approved centers where all of the above criteria are satisfied.

\section{ONLINE DEGREES IN THE EYES OF EMPLOYERS}

Despite the increasing interest in pursuing an online degree toward obtaining additional credentials, the economic climate causes students to place a high premium on whether online degrees translate into jobs or careers. This translation is dependent on the current hiring practices that are influenced by the employers' views. The following is a typical outcome of recent studies of how employers look at the type of undergraduate degrees.

Adams and DeFleur [21] studied the perceptions about online bachelor's degrees in the entry-level position hiring process. They compared companies' perception to three types of degrees: traditional bachelor degree, bachelor degree achieved through a mix of delivery methods and some courses taken face-to-face and others taken online, and bachelor degree taken from a virtual university, i.e. completely online. The completed 269 surveys were then analyzed. The findings suggest that when companies attempted to fill management or entry level positions in accounting, business, engineering, and information technology, 96 percent indicated that they would choose the candidate with a traditional degree. When comparing traditional degree to hybrid delivery, 75 percent would still prefer traditional over the hybrid. In addition, 72 percent answered "yes" to the question whether the type of degree makes a difference in the decision to select a candidate. The quantitative findings further suggested that concerns such as accreditation, perceived interaction among peers and professor, quality, skills, and work experience were the most predominant reasons not to hire an online candidate. The study by Guendoo [22] involved 52 administrators of the largest 145 community colleges in the United States found that they did not view the online degree as a hindrance to a recipient's chances for employment. It is important to note that almost all the respondents had experience with taking and/or teaching online courses. "One can predict that the gap in perception between the subjects of this study (community college leaders) and those of the Adams and DeFleur [21] study for traditional four-year colleges will continue to close over time". In [23], Jonathan Adams; an associate professor at Florida State University's College of Communication sent surveys to hiring managers around the country in 2005, asking them to choose between two similarly qualified fictional applicants-one with a traditional degree and one with a degree from an online institution. Out of 269 responses, 96 percent chose the applicant with the traditional degree. Hiring managers perceive the online degrees to be of a lower quality. Besides these types of study, we must point out that employers are not education specialists; and that their opinions of the type of earned degrees are based on the information available on the market. The other fact is that some universities termed "Degree Mills" award diplomas not worth much more than the paper they are printed on. Columbaro and Monaghan [24] reported that, throughout empirical studies, potential employers are reticent about accepting online degree credentials because of

- lack of face-to-face interactions,

- increased potential for academic dishonesty,

- $\quad$ association with diploma mills,

- concerns about online students' true commitment.

On the other hand, from empirical studies and popular media, conditions that could influence online degree acceptance in the hiring process were:

- name recognition/reputation of the degree-granting institution,

- appropriate level and type of accreditation,

- perception that online graduates were required to be more self-directed and disciplined,

- candidates' relevant work experiences,

- $\quad$ and whether the online graduates were being considered for promotion within an organization or if they were competing for new positions elsewhere or in a new field.

Even though e-learning strives to achieve what conventional learning is doing: (1) e-learning is providing the same courses content as conventional learning does, (2) e-learning tries to provide the same qualifications as conventional learning does, and (3) the difference between the two approaches of learning is on how to achieve these goals, the above studies show that some employers in the advanced world are still suspicious about online degrees. In other parts of the world online degrees holders are victims of the publicity of "university mills".

\section{CONCLUSION}

Learning is one of our important life issues that can benefit from the cutting edge technologies. Information and 
communication technology is a valuable tool that improves the learning process if used efficiently. In online learning, learners are freed from many constraints hindering them from fulfilling their will to achieve higher levels of knowledge and consequently improve their job positions. They can learn anywhere, anytime, and at their own pace. In addition, the required cost for earning degrees can be minimized. This is the positive side of the picture. On the other hand, excessive confidence towards information and communication technologies in a learning discipline may lead to a situation similar to the dot-com burst that happened in the late 2000 . The period from 1990-2000 was marked by the founding of a group of new Internet-based companies commonly referred to as dot-com. Companies were seeing their stock prices raise if they simply added an "e-" prefix to their name and/or a ".com" to the end. The bubble caused an overvaluation of the companies. This resulted in the burst of the bubble which in turn resulted in the worth of shares becoming a small fraction of their value at the height of the boom, and many companies went out of business.

E-learning can be categorized according to individual needs of learners. In this regard, a learner can be someone seeking to improve his/her competencies in order to compete with new market demands. On the other hand, he/she also can be a student looking for a degree. The latter case encompasses two categories of individuals, either serious students who are unable to join education institutions or others whose objective is strictly limited to have a certificate.

For the last category of students, e-learning experts should prevent the dot-com scenario from reproducing in the learning discipline; otherwise we will get to a point where an unlimited number of degrees are offered to people who do not participate in any learning activity. To preserve the educational standards on the one hand, and guarantee confidence in online learning on the other, summative assessment for online learning should be held at some points in time for instance twice per semester, at specific locations under the vigilance of teachers, whatever the tools used to educate and to evaluate.

\section{REFERENCES}

[1] G. M. Farrell. (2001). The Changing Faces of Virtual Education, $\odot$ The Commonwealth of Learning (Eds.). [Online]. Available: http://www.col.org/resources/publications/Pages/detail.aspx?PID=17 6

[2] T. Volery, "Critical success factors in online education," The International Journal of Educational Management, vol. 14, no. 5, pp. 216-223, 2000.

[3] T. Ribiero, "From a distance: Look at distance learning's increased following," Education, vol. 152, no. 9, pp. 85, 2002.

[4] L. Darling, "Your e-learning Strategy: Make sure it's learning for results," Training, vol. 39, no. 3, pp. 2, 2002.

[5] D. Hartley, "All aboard the e-learning Train," Training and Development, vol. 54, no. 7, pp. 37, 2000.

[6] S. Guri-Rosenblit, "Eight paradoxes in the implementation process of e-learning in higher education," Higher Education Policy, vol. 18, no.1, pp. 5-29, 2005.

[7] J. O'Hearn, "Challenges for service leaders: setting the agenda for the virtual learning organization," International Journal of Contemporary Hospitality Management, vol. 12, no. 2, pp. 97-106, 2000.
[8] A. Shirley, "E-learning developments and experiences," Education and Training, vol. 43, pp. 240-248, 2001.

[9] R. Bennett, and S. McIntyre, "Post the E-learning Goldrush: Encouraging Purpose and Quality in New Online Art and Design Courses," in Proc. the Australian Council of University Art and Design Schools Conf., Canberra, Australia, September, 2004, pp. 22-25.

[10] C. A. Twigg. (2003). Program in course redesign. National Centre for Academic Transformation [Online]. Available: http://www.thencat.org/PCR/Outcomes.htm

[11] C. D. Dziuban, J. L. Hartman, and P. D. Moskal. (2004). Blended Learning [Online]. Available: http://net.educause.edu/ir/library/pdf/ERB0407.pdf

[12] C. Garnham, and R. Kaleta, "Introduction to hybrid courses," Teaching with Technology Today, vol. 8, no. 6, 2002.

[13] P. Spika. (2002). Approximately "real world" learning with the hybrid model. Teaching with Technology Today [Online]. 8(6). Available: http://www.uwsa.edu/ttt/articles/spilka.htm

[14] A. Rossett, F. Douglis, and R. V. Frazee. (June 2003). Strategies for Building Blended Learning, Learning Circuits, American Society for Training and Development. [Online]. available: http://dimadele.org/platform10/blended_learning/Blended\%20Learni ng.pdf

[15] G. Gibbs and H. Dunbat-Goddet. (February 2007). The effects of programme assessment environments on student learning, Oxford Learning Institute University of Oxford. [Online]. Available: http://www.heacademy.ac.uk/resources/detail/teachingandresearch/th e_effects_of_programme_assessment_environments_on_student_lear ning.

[16] G. Conole and B. Warburton, "A review of computer-assisted assessment," ALT-J, Research in Learning Technology, vol. 13, no. 1, pp. 17-31, 2005.

[17] Commission for academic accreditation, ministry of higher education and scientific research, United Arab Emirates, 2004. E-Learning Accreditation Standards. [Online]. Available: http://www.caa.ae/caaweb/images/elearningguidebook.pdf.

[18] D. Booth, M. Butler, D. Emery, R. Horan, W. Middleton, and W. Pountney, "Issues for web delivered assessment," in Proc. the Twenty Seventh Undergraduate Mathematics Teaching Conf., Birmingham, 2001, pp. 56-64.

[19] J. Engelbrecht, and A. Harding, "Teaching Undergraduate Mathematics on the Internet Part 1: Technologies and Taxonomy," Educational Studies in Mathematics, vol. 58, no. 2, pp. 235-252, 2005.

[20] TOEFL® ITP Assessment Series. (2010). Test Administration Procedures. [Online]. Available: www.iielatinamerica.org/descargas2/TOEFL_ITP_Supervisors_Manu al_83504_Final.pdf

[21] J. Adams, and M. DeFleur, "The acceptability of online degrees earned as a credential for obtaining employment," Communication Education, vol. 55 , no. 1 , pp. 32-45, 2006.

[22] L. Guendoo, "Credibility Challenges to Online Doctoral Graduates Seeking Faculty positions: A Community College Perspective," Doctoral dissertation, Capella University, Minnesota, USA, 2007.

[23] J. Adams, "Chronicle of Higher Education," vol. 53, no. 18, pp. A28, January 2007.

[24] N. L. Columbaro and H. Catherine, "Monaghan Employer Perceptions of Online Degrees: A Literature Review," Online Journal of Distance Learning Administration, vol. 12, no. 1, Spring 2009.

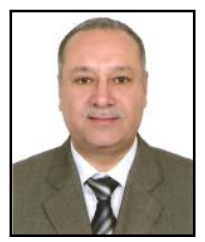

Tayeb Basta was born in Algeria, 1960. Tayeb received a BSC degree of computer science in 1983 from University of Annaba, Algeria, and a Ph.D. degree from University of Manchester, UK in 1994. Tayeb is now a faculty member at AlGhurair University in Dubai, UAE. Basta is a senior member of IACSIT and SIE. 